\title{
Força de tração e potência de uma semeadora em duas velocidades de deslocamento e duas profundidades de deposição de sementes
}

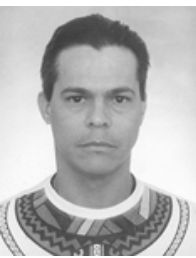

\author{
João C. M. da Silveira ${ }^{1}$, Alcir J. Modolo² ${ }^{2}$ Suedêmio de L. Silva ${ }^{3} \&$ Antonio Gabriel Filho ${ }^{3}$ \\ 1 UNIOESTE/CCET/Eng. Agrícola/Laboratório de Máquinas e Mecanização Conservacionista. Av. Joaquim Lopes de \\ Faria, Santo Antônio. Viçosa, MG. Fone: (45) 226-1125. E-mail: jcmodernel@uol.com.br (Foto) \\ ${ }^{2}$ DEA/UFV, Av. Joaquim Lopes de farias, CEP 36570-000, Viçosa, MG. Fone: (31) 3891-0597. E-mail: alcir@vicosa.ufv.br \\ ${ }^{3}$ UNIOESTE/CCET. E-mail: suedemio@unioeste.br; gabriel@unioeste.br
}

Protocolo 1 - 3/1/2003 - Aprovado em 2/4/2004

\begin{abstract}
Resumo: Para este trabalho, avaliou-se o requerimento de força de tração de uma semeadora de fluxo contínuo com 14 linhas, na semeadura da aveia preta (Avena strigosa L.) em experimento conduzido em um Latossolo Vermelho distroférico, numa área com declividade média de 0,03 $\mathrm{m} \mathrm{m}^{-1}$. O delineamento experimental foi constituído de quatro tratamentos (duas profundidades de deposição de sementes e a duas velocidades de deslocamento) com quatro repetições, totalizando dezesseis parcelas experimentais de $4 \times 50 \mathrm{~m}\left(200 \mathrm{~m}^{2}\right)$ em sistema de plantio direto sob resteva de milho. Com o aumento da profundidade de deposição de sementes de 1,97 cm para 2,68 cm, o requerimento de força de tração aumentou de 3,78 kN para $5,51 \mathrm{kN}$. O aumento da velocidade de deslocamento de $5,24 \mathrm{~km} \mathrm{~h}^{-1}$ para $7,09 \mathrm{~km} \mathrm{~h}^{-1}$, provocou acréscimo de $6,90 \%$ no requerimento de força de tração na barra.
\end{abstract}

Palavras-chave: semeadora de fluxo contínuo, força de tração, velocidade de deslocamento

\section{Traction and power required by a seed drill with two speeds of displacement and two sowing depths}

\begin{abstract}
Traction and power required by a seed drill with 14 holes was evaluated in the oat (Avena strigosa $L$ ) seeding. The experiment was carried out in a Haplortox, in an area with mean slope of $0.03 \mathrm{~m} \mathrm{~m}^{-1}$. The experimental design consisted of four treatments (two seed deposition depths and two displacement speeds) with four repetitions, totaling sixteen experimental plots of

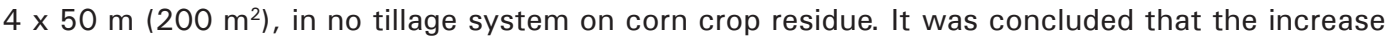
of the seeding depth of $1.97 \mathrm{~cm}$ to $2.68 \mathrm{~cm}$, the draft requirement increased from 3.78 to 5.51 $\mathrm{kN}$. The speed increase from 5.24 to $7.09 \mathrm{~km} \mathrm{~h}^{-1}$, caused an increase of $6,90 \%$ in the traction force of the drawbar.
\end{abstract}

Key words: seed drill, draft, velocity

\section{INTRODUÇÃO}

Com a utilização de máquinas e implementos agrícolas, a agricultura mundial deixou de ser de subsistência para se tornar capaz de fornecer produto para todos os mercados. A maneira de semear a terra também mudou; antes, praticava-se a agricultura convencional, que consistia em várias operações de preparo do solo e no tráfego intensivo de máquinas e implementos, acarretando ao solo grandes problemas, principalmente a erosão; surge, então, o sistema conser- vacionista, que tem como objetivo reduzir o número de operações de preparo do solo, além de controlar a erosão.

Para Larson \& Gill (1973), os sistemas conservacionista devem ser poupadores de energia, como também, promover condições adequadas para a implantação de culturas. No entanto, os efeitos desses sistemas sobre o desempenho máquinas de semeadura, não são ainda suficientemente conhecidos, necessitando cada vez mais novos estudos sobre estes sistemas.

Com a cobertura de inverno recuperam-se solos danificados, reduz-se $\mathrm{o}$ ataque de pragas e doenças e se controlam as ervas 
invasoras e nematóides; aumenta-se a capacidade do solo de armazenar água e, a médio e longo prazo, reduz-se à erosão (EMATER-DF, 2001).

Furlani et al. (1999) citam que, com a necessidade de se produzir mais alimentos, alguns sistemas de produção vêm esgotando e empobrecendo os solos, pois estão sendo explorados de maneira inadequada. A prática de manejo e conservação do solo surgiram com o uso da semeadura direta, impedindo o empobrecimento das áreas de plantio.

Avaliando o desempenho de uma semeadora-adubadora de fluxo contínuo, em semeadura de aveia preta (Avena strigosa L.) em diferentes preparos de solo, Levien et al. (2000) concluíram que as condições de superfície originadas pelo preparo dos solos influenciaram variáveis operacionais e energéticas na operação da aveia.

Em dinâmica de semeadoras-adubadoras diretas na cidade de Marechal Cândido Rondon,PR, Casão Júnior et al., (2001) avaliaram cinco modelos de semeadoras-adubadoras de fluxo contínuo e concluíram que todas as máquinas apresentaram variação em relação ao valor médio para profundidade de sementes, superior a $20 \%$ e, em algumas situações, superior a $40 \%$. Os mesmos autores concluiram que a semeadora com melhor desempenho exigiu menor força de tração por linha $(39,1 \mathrm{kgf})$.

Estima-se que, para operar uma semeadora-adubadora de fluxo contínuo por linha de semeadura a força de tração é de $0,4 \mathrm{kN}$ para o preparo convencional e de $0,7 \mathrm{kN}$ para o plantio direto (ASAE,1999).

Silva et al. (2000) verificaram que a força de tração média requerida na barra de tração não sofreu variação significativa com a variação da velocidade. O maior requerimento de força de tração ocorreu na maior velocidade de deslocamento e o requerimento de força de tração por unidade de semeadura foi de $2,920 \mathrm{kN}$.

Em trabalho conduzido em Terra Roxa estruturada, Levien et al. (1999) constataram que a força de tração exigida por uma semeadora-adubadora de precisão variou entre 3,240 a 3,636 $\mathrm{kN}$ por linha entre todos os tratamentos avaliados (preparo convencional, escarificação, semeadura direta sem manejo da cobertura e semeadura direta com manejo de cobertura).

Para testar algumas das variáveis influenciadoras da demanda de tração na semeadura da aveia preta sobre resteva de milho, Levien et al. (2001) encontraram valores de força de tração exigida por linha de semeadura de 0,$31 ; 0,33$ e 0,28 para os sistemas de preparo do solo convencional, escarificado e plantio direto, respectivamente. Portanto abaixo dos valores preconizados pela ASAE (1999).

Ao avaliar o desempenho de uma semeadora-adubadora de fluxo contínuo, Furlani et al. (2002) concluíram que a potência exigida na barra foi maior no preparo do solo escarificado do que no preparo convencional e plantio direto.

Assim, objetivou-se, neste trabalho, avaliar a força de tração e a potência requerida por uma semeadora de fluxo contínuo, em duas velocidades de deslocamento e duas profundidades de deposição de sementes, em plantio direto.

\section{MATERIAL E MÉTODOS}

O experimentos foi conduzido no Núcleo Experimental de Engenharia Agrícola - NEEA, pertencente à Universidade Estadual do Oeste do Paraná - Campus de Cascavel, Estado do Paraná, situado lateralmente no km 95 da BR 467, sentido Cascavel - Toledo. A localização geográfica está definida pelas coordenadas $24^{\circ} 48^{\prime}$ de latitude Sul e $53^{\circ} 26^{\prime}$ de longitude Oeste, com altitude média de $760 \mathrm{~m}$ e declividade situada entre 0,0 e $0,03 \mathrm{~m} \mathrm{~m}^{-1}$. O solo da área experimental foi classificado, segundo EMBRAPA (1999), como sendo Latossolo Vermelho distroférrico, com relevo plano e de textura argilosa.

O delineamento foi constituído por quatro tratamentos (duas velocidades de deslocamento - V1: velocidade média de deslocamento de $5,24 \mathrm{~km} \mathrm{~h}^{-1}$, V2: velocidade média de deslocamento de $7,09 \mathrm{~km} \mathrm{~h}^{-1}$; e duas regulagens de profundidade de deposição de sementes - P1: profundidade média de deposição de semente de 1,97 cm, P2: profundidade média de deposição de semente de 2,68 cm); em blocos ao acaso, com quatro repetições, totalizando dezesseis unidades experimentais. Cada unidade experimental possuía $4 \mathrm{~m}$ de largura por $50 \mathrm{~m}$ de comprimento, perfazendo uma área de 200 $\mathrm{m}^{2}$. Entre os blocos deixaram-se $15 \mathrm{~m}$ de comprimento para o tráfego do conjunto motomecanizado, manobras e estabilização do conjunto antes do início da aquisição de dados. Para se verificar a influência da velocidade de deslocamento no requerimento de força de tração média, realizou-se uma análise fatorial.

Foi utilizado um trator da marca FORD, modelo $76304 \times 2$, com tração dianteira auxiliar (TDA), potência de 75,8 kW (103 $\mathrm{CV}$ ) no motor a $2100 \mathrm{rpm}$ e massa em ordem de embarque de $3.580 \mathrm{~kg}$ e $6.196 \mathrm{~kg}$ com lastragem máxima. Para a operação de semeadura, usou uma semeadora de arrasto marca Vence Tudo, modelo SMT 6414 - Série 07, com 14 linhas para sementes miúdas, mecanismos sulcadores para fertilizantes e sementes do tipo discos duplos desencontrados e mecanismo distribuidor de sementes do tipo cilindro acanalado reto. A especificação técnica da semeadora pode ser observada na Tabela 1.

Um sistema de aquisição de dados "Micrologger 23X" foi empregado para armazenar e gravar continuamente os sinais gerados pelos transdutores instalados no conjunto motomecanizado. Foram monitorizados o requerimento de força de

Tabela 1. Especificações técnicas da semeadora SMT 6414 Série 07, marca Vence Tudo

$$
\text { Parâmetros }
$$

Número de linhas

Espaçamento entre linhas $(\mathrm{cm})$

Capacidade de sementes $(\mathrm{kg})$

Capacidade de fertilizantes $(\mathrm{kg})$

Peso aproximado $(\mathrm{kg})$

Potência mínima do trator $(\mathrm{cv})$

Bitola dos pneus e pressão de trabalho $6,50 \times 16-40$ a $45 \mathrm{lbs} \mathrm{pol}^{-2}$

Perímetro da roda motriz $(\mathrm{m})$

Largura útil (mm)

Altura (mm)

Correntes cobridoras de sulco

\section{Características}

14

17

180

425

1417

75

2,246

3370

1900

argolas 
tração na barra, patinagem das duas rodas traseiras do trator e a velocidade de deslocamento. Para monitorar o requerimento de força de tração na barra solicitada pela semeadora, lançouse mão de uma célula de carga marca SODMEX com capacidade para $50 \mathrm{kN}$, inserida entre o trator e a semeadora. A velocidade de deslocamento foi determinada por uma unidade de radar da marca "Dickey-John", modelo DjRVS, com erro menor que 3\% para velocidades de 3,2 a 7,08 $\mathrm{km} \mathrm{h}^{-1}$; já os transdutores foram alimentados a partir da bateria interna do "micrologger", enquanto os dados foram armazenados pelo "micrologger" e posteriormente transferidos para um computador.

Todos os parâmetros com as análises estatísticas referentes aos dados obtidos nos experimentos e os valores calculados foram comparados pelo teste de Tukey a $5 \%$ de significancia.

\section{RESULTADOS E DISCUSSÃO}

O teor médio de água do solo, no dia da semeadura, foi de $35,7 \%$ na camada de 0 a $10 \mathrm{~cm}$ e o valor médio encontrado para a densidade do solo antes da operação de semeadura na camada de 0 a $10 \mathrm{~cm}$, foi de $1,31 \mathrm{~g} \mathrm{~cm}^{-3}$.

Os valores médios da profundidade de deposição de sementes mostrados na Figura 1, apresentaram valores com diferença estatisticamente significativa entre os tratamentos, já esperado, uma vez que se regulou a semeadora em duas profundidades distintas de deposição de sementes. Os tratamentos P1V1 e P1V2 e os P2V1 e P2V2 não apresentaram diferenças estatísticas significativas entre si, ou seja, quando operados nas duas velocidades de deslocamento e na mesma profundidade de deposição de sementes.

Os valores obtidos para as velocidades de deslocamento do conjunto trator/semeadora nos quatro tratamentos, estão inseridos na Tabela 2, e a diferença estatística significativa encontrada se deve a duas velocidades distintas de deslocamento. Observa-se que a velocidade média de deslocamento não é afetada pela profundidade de deposição de sementes (Tabela 2) e, também, que o trator conseguiu manter a mesma velocidade de deslocamento quando a profundidade de deposição de semente variou de 1,97 para 2,68 cm.

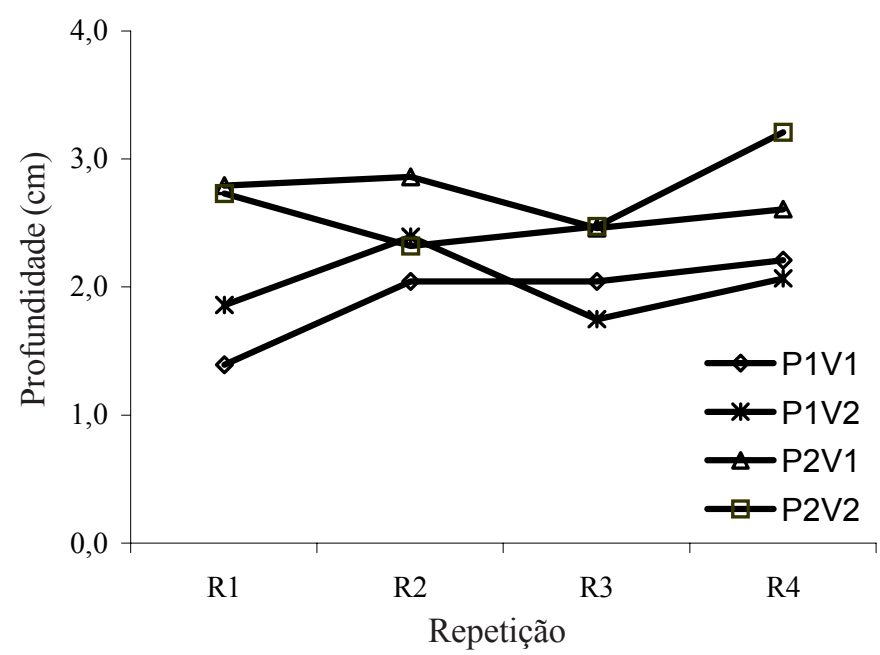

Figura 1. Profundidade de deposição de sementes $(\mathrm{cm})$ mensurada a duas velocidades de deslocamento e a duas profundidades de deposição de sementes
Tabela 2. Velocidade de deslocamento $\left(\mathrm{km} \mathrm{h}^{-1}\right)$ do conjunto trator/semeadora no experimento

\begin{tabular}{|c|c|c|c|c|c|}
\hline \multirow{2}{*}{ Tratamentos } & \multicolumn{4}{|c|}{ Repetições } & \multirow[b]{2}{*}{ Média* } \\
\hline & $\mathrm{R} 1$ & $\mathrm{R} 2$ & R3 & $\mathrm{R} 4$ & \\
\hline P1V1 & 5,18 & 5,27 & 5,26 & 5,35 & $5,27 \mathrm{~B}$ \\
\hline P1V2 & 6,89 & 7,20 & 7,13 & 7,13 & $7,09 \mathrm{~A}$ \\
\hline P2V1 & 5,20 & 5,21 & 5,15 & 5,28 & $5,21 \mathrm{~B}$ \\
\hline $\mathrm{P} 2 \mathrm{~V} 2$ & 7,10 & 7,06 & 7,07 & 7,11 & $7,09 \mathrm{~A}$ \\
\hline Média & 6,09 & 6,19 & 6,15 & 6,22 & 6,16 \\
\hline $\mathrm{CV}=1,16 \%$ & \multicolumn{2}{|c|}{$\mathrm{DP}=0,07 \mathrm{~km} \mathrm{~h}^{-1}$} & \multicolumn{3}{|c|}{$\mathrm{DMS}_{\text {Tratamento }}=0,16 \mathrm{~km} \mathrm{~h}^{-1}$} \\
\hline
\end{tabular}

Os valores médios do requerimento de força de tração $(\mathrm{kN})$ na barra requerida pela semeadora são apresentados na Tabela 3, na qual se observa que os tratamentos P1V1 e P1V2 não diferiram estatisticamente, o mesmo acontecendo com os tratamentos P2V1 e P2V2. Apesar da profundidade de deposição de sementes não afetar significativamente o requerimento de força de tração, a velocidade de deslocamento provocou aumento no requerimento de força, de 12,08 e 3,70\%, para as profundidades $\mathrm{P} 1$ e P2, respectivamente, quando esta passou de 5,24 para 7,09 $\mathrm{km} \mathrm{h}^{-1}$. Os valores obtidos para força de tração média por linha, são de 0,27 e $0,40 \mathrm{kN}$ para as profundidades $\mathrm{P} 1$ e P2, respectivamente, concordando com os valores encontrados por Levien et al. (2000) para a profundidade P1.

A força de tração máxima (pico) na barra se deve à irregularidade do terreno, à diferença de profundidade de semeadura e embuchamentos momentâneos. Na Tabela 3 são apresentados os valores médios da força de tração máxima na barra obtidos no experimento, em que se observa que o maior pico foi verificado no tratamento P2V2, onde ocorreram as maiores profundidades de deposição de sementes e velocidade de deslocamento, enquanto o menor pico foi para o tratamento P1V1, com a menor profundidade de deposição de semente e menor velocidade de deslocamento.

A diferença entre o menor e o maior pico foi de 51,19\% para a profundidade $\mathrm{P} 1$, quando a velocidade de deslocamento passou de 5,24 para $7,09 \mathrm{~km} \mathrm{~h}^{-1}$, e a força de tração máxima na barra aumentou 24,60\%; já para a profundidade $\mathrm{P} 2$, este aumento de velocidade fez com que a força aumentasse 5,10\% e, com o aumento da força de tração, aumenta-se também o valor dos picos de força (Tabela 3 ).

Para a influência da velocidade de deslocamento no requerimento de força de tração média, optou-se por uma análise fatorial, cujo resultado pode ser visto na Tabela 4. Tanto a

Tabela 3. Força de tração $(\mathrm{kN})$ média e máxima na barra pela semeadora mensurada a duas velocidades de deslocamento e a duas profundidades de deposição de sementes

\begin{tabular}{ccc}
\hline \multirow{2}{*}{ Tratamento } & \multicolumn{2}{c}{ Força de tração* - kN } \\
\cline { 2 - 3 } & Média & Máxima \\
\hline P1V1 & $3,56 \mathrm{~B}$ & $5,04 \mathrm{C}$ \\
P1V2 & $3,99 \mathrm{~B}$ & $6,28 \mathrm{~B}$ \\
P2V1 & $5,41 \mathrm{~A}$ & $7,25 \mathrm{AB}$ \\
P2V2 & $5,61 \mathrm{~A}$ & $7,62 \mathrm{~A}$ \\
Média & 4,64 & 6,55 \\
\hline * Médias seguidas de mesma letras maiúsculas nas colunas ou de mesma letras minúsculas na linha, \\
não diferem estatisticamente entre si, pelo teste de Tukey, a nivel de 5\% de probabilidade.
\end{tabular}
* Médias seguidas de mesma letras maiúsculas nas colunas ou de mesma letras minúsculas na linha,
não diferem estatisticamente entre si, pelo teste de Tukey, a nível de $5 \%$ de probabilidade. 
Tabela 4. Força de tração $(\mathrm{kN})$ média na barra pela semeadora, mensurada a duas velocidades de deslocamento e a duas profundidades de deposição de sementes

\begin{tabular}{|c|c|c|c|}
\hline \multirow{2}{*}{ Velocidade } & \multicolumn{2}{|c|}{ Profundidade } & \multirow[b]{2}{*}{ Média } \\
\hline & $\mathrm{P} 1$ & P2 & \\
\hline V1 & 3,56 & 5,41 & $4,49 \mathrm{~B}$ \\
\hline $\mathrm{V} 2$ & 3,99 & 5,61 & $4,80 \mathrm{~A}$ \\
\hline Média & $3,78 \mathrm{~b}$ & $5,51 \mathrm{a}$ & 6,64 \\
\hline $\mathrm{CV}=5,41 \%$ & \multicolumn{2}{|c|}{$\mathrm{DP}=0,25 \mathrm{kN}$} & $\mathrm{DMS}_{\text {Tratamento }}=0,56 \mathrm{kN}$ \\
\hline
\end{tabular}

*As médias seguidas pelas mesmas letras não diferenciam, pelo teste de Turkey a 0,05 de probabilidade

Tabela 5. Potência $(\mathrm{kW})$ média e máxima na barra requerida pela semeadora, mensurada a duas velocidades de deslocamento e a duas profundidades de deposição de sementes

\begin{tabular}{ccc}
\hline \multirow{2}{*}{ Tratamento } & \multicolumn{2}{c}{ Potência* - kW } \\
\cline { 2 - 3 } & Média & Máxima \\
\hline P1V1 & $07,20 \mathrm{C}$ & $13,73 \mathrm{C}$ \\
P1V2 & $10,80 \mathrm{~B}$ & $25,75 \mathrm{~B}$ \\
P2V1 & $10,83 \mathrm{~B}$ & $29,84 \mathrm{~B}$ \\
P2V2 & $15,37 \mathrm{~A}$ & $44,28 \mathrm{~A}$ \\
Média & 11,05 & 28,40 \\
\hline *As médias seguidas pelas mesmas letras não diferenciam, pelo teste de Turkey a 0,05 de probabilidade
\end{tabular}

velocidade de deslocamento como a profundidade de deposição de sementes afetaram o requerimento de força de tração, mas a interação da profundidade de deposição de semente versus velocidade de deslocamento, não foi significativa. $\mathrm{O}$ aumento da velocidade de deslocamento de 5,24 para 7,09 $\mathrm{km} \mathrm{h}^{-1}$, provocou aumento de $6,90 \%$ no requerimento de força na barra de tração. Collins \& Fowler (1996) encontraram valores semelhantes para cada incremento de velocidade.

A Tabela 5 mostra os valores da potência média $(\mathrm{kW})$ requerida na barra pela semeadora-adubadora. Verificou-se que a maior demanda de potência $(15,37 \mathrm{~kW})$ foi encontrada para a profundidade $\mathrm{P} 2(2,68 \mathrm{~cm})$ e na velocidade de deslocamento V2 $\left(7,09 \mathrm{~km} \mathrm{~h}^{-1}\right)$, o qual apresentou maior requerimento de força de tração, conforme a Tabela 4; um aumento de 26,09\% na velocidade de deslocamento causou acréscimos de $50,00 \%$ e $41,92 \%$ no requerimento de potência média na barra para as profundidades $\mathrm{P} 1$ e P2, respectivamente. Ainda na mesma tabela tem-se os valores do requerimento de potência máxima $(\mathrm{kW})$ na barra, solicitados pela semeadora. Observa-se que, para uma mesma profundidade de deposição de sementes, a velocidade de deslocamento provocou aumento de potência de 87,55 e $48,39 \%$ para as profundidades $\mathrm{P} 1 \mathrm{e} \mathrm{P} 2$, respectivamente, quando esta passou de 5,24 para 7,09 $\mathrm{km} \mathrm{h}^{-1}$. Comparando-se o valor médio geral dos picos com os valores médios de potência, vêse um aumento da ordem de $157,01 \%$, enquanto a diferença entre a força de tração média e a máxima (pico) na barra foi de $41,16 \%$.

\section{CONCLUSÕES}

1. Com o aumento da profundidade de deposição de sementes de 1,97 para 2,68 cm, o requerimento de força de tração, também aumentou, de 3,78 para $5,51 \mathrm{kN}$.
2. O aumento da velocidade de deslocamento de 5,24 para $7,09 \mathrm{~km} \mathrm{~h}^{-1}$, provocou aumento de $6,90 \%$ no requerimento de força de tração na barra.

\section{LITERATURA CITADA}

ASAE - American Society of Agricultural Engineers. Agricultural machinery management. In: ASAE Standards 1999: Standards engineering practices data. St. Joseph, 1999. p.359-366. ASAE D 497.4 Jan. 98.

Casão Júnior, R., Siqueira, R., Araújo, A.G. Dinâmica de semeadoras-adubadoras diretas em Marechal Cândido Rondon - PR.: Resultados de avaliação. Londrina: IAPAR, 2001, 26 p.

Collins, B.A.; Fowler, D.B. Effects of soil characteristics depth, operating speed, and opener design on draft force during direct seeding. Soil \& Tillage Research, Amsterdam, v.39, p.199-211, 1996.

EMATER-DF. Empresa de Assistência Técnica e Extensão Rural do Distrito Federal. Adubação verde. Acessado em 23 de agosto de 2001. On line disponível na internet em http:// www.emater.df.gov.br/grãos/ADUBVERD.HTM

EMBRAPA. Sistema brasileiro de classificação de solos. Brasília: Serviço de Produção de Informação, 1999. 412p.

Furlani, C.E.A.; Abrahão, F.Z.; Lopes, A.; Leite, M.A.S. Influência na velocidade de semeadura na cultura do milho (Zea mays) em diferentes condições de preparo do solo. In: Congresso Brasileiro de Engenharia Agrícola, 28, 1999, Pelotas, RS. Anais...Pelotas: Sociedade Brasileira de Engenharia agrícola, 1999, CD-ROM

Furlani, C.E.A.; Gamero, C.A.; Levien, R. Semeadora-adubadora de fluxo contínuo: Desempenho operacional em função de diferentes condições de preparo e cobertura do solo. Engenharia Agrícola, Jaboticabal, v. 22, n.1, p. 60-67, 2002.

Larson, W.E.; Gill, W.R. Soil physical parameters for designing, new tillage systems. In: National Conservation Tillage Conference, 1, 1973, Ankeny, Anais...p.13-22.

Levien, R.; Gamero, C.A.; Furlani, C.E.A. Desempenho de uma semeadora-adubadora de fluxo contínuo, em semeadura de aveia preta (Avena strigosa L.), sob diferentes preparos de solo. In: Congresso Brasileiro de Engenharia Agrícola, 29, 2000, Fortaleza, CE. Anais...Fortaleza: Sociedade Brasileira de Engenharia Agrícola, 2000, CD-ROM

Levien, R.; Gamero, C.A.; Furlani, C.E.A. Desempenho de uma semeadora-adubadora de fluxo contínuo, em semeadura de aveia preta após a cultura do milho, sob diferentes preparos do solo. Engenharia Agrícola, Jaboticabal, v. 21, n.2, p. 145151, 2001.

Levien, R.; Marques, J.P.; Benez, S.H. Desempenho de uma semeadora-adubadora de precisão, em semeadura de milho (Zea mays $L$ ), sob diferentes formas de manejo do solo. In: Congresso Brasileiro de Engenharia Agrícola, 28, 1999, Pelotas, RS. Anais...Pelotas: Sociedade Brasileira de Engenharia Agrícola, 1999, CD-ROM

Silva, S. de L.; Benez, S.H.; Ricieri, R.P.; Pereira, J.O. Demanda energética em sistema de semeadura direta em milho. In: Congresso Brasileiro de Engenharia Agrícola, 29, Fortaleza, CE. 2000. Anais... Sociedade Brasileira de Engenharia Agrícola, 2000, CD-ROM 